ISBN 978-93-84468-86-6

2016 International Research Conference on Social Sciences, Humanities and Interdisciplinary Studies

(RCSSHIS-2016)

Pattaya (Thailand) Dec. 16-17, 2016

\title{
Consumer Buying Behaviors of Household Plastic Furniture Company
}

\author{
Dr. Chinnaso Visitnitikija, and Suparat Kanapongratthorn \\ chinnaso12@gmail.com \\ Post gaduate School of business administration \\ Kasembundit University, Bangkok
}

\begin{abstract}
The primary purpose of the study was to determine customer buying behaviors and marketing factors of household plastic furniture. The samples were selected from 400 customers who are consumer live in Bangkok area by using a check list and rating scale questionnaire as a tool. Statistical application used for data analysis was percentage, mean, standard deviation, Chi-Square, and regression analysis.

On the basis of the results of this study, it could be concluded that most of respondents were females, age between 31-45 years old, earned high school or vocational school, average monthly income between 9,000-15,000 baht, most of consumer purchased Sri Thai Super ware brand name for furniture styles, friends influenced in selection, purchase during sale promotion, bought from whole sale stores, and purchased every 6 months. Marketing mix which effecting customer buying behaviors of household plastic furniture was in high level, such as marketing promotion, discount price during new products offered, and offered discount prices when buying with large quantity. As for products aspect, such as purchased for the reason of durable items, product guaranteed, proper color, well known brands of household plastic furniture, modern styles, and appropriated prices. Hypothesis testing revealed that factors of personal different, such as gender, age, level of education, and monthly income effected customer buying behaviors of household plastic furniture and factors of marketing mix correlated to customer buying behaviors of household plastic furniture. In regard to the pricing aspect, such as different prices, and distribution channel nationwide and have representative to introduce products as for market promotion were in statistical significant 0.05 level.

Recommendations from this study were that entrepreneur should focus on modern product design as first priority, meet the needs of consumer preferred, comparable prices to other distributors, retail stores nationwide, discount prices when introducing new products, free gift with purchased, and advertising through all media channels.
\end{abstract}

Keywords: Consumer Buying Behaviors

\section{Introduction}

In present time, there are a variety of plastic products which categorized into two types, the first type is the plastic products that use labor intensive, such as plastic bags, sacks, films, and foils. The others type are plastic products that create value, such as home appliances, tableware, office furniture, packaging, apparel, etc. which are components of the products in this type. The development of products and quality are important because products that are often focus on middle to upper market. The importance of such plastics industry, both government and private business entrepreneur sector foresee necessity for strategic planning of the development of plastics industry which included industrial master plan. The rising of global market, especially from China which is developing rapidly in the plastics industry, including from Asian countries such as Malaysia, Indonesia, and Viet Nam, therefore the aggressive strategy urgently needed for Thai plastics products industry. Kasikorn Thai Research Center stated the opinion that proactive strategies to expand export aspects, such as distribution of products to new market potential (e.g. countries in Eastern Europe and some countries in Africa) rather than in 
the main market such as United States, Japan, Asian countries, Western Europe, and Australia for example. The development of wide range of new products should comply with requirement of consumer in each market and each market with difference requirement. Thai Plastics industry from (Admin, 2547).

http://positioningmag.com/18857).

Currently, the plastic products have high market competition. There are industrial factories both domestic and international markets, especially China, a rival market with a variety of products, price, quality in many brands, and have new products design to compete in the market continuously which allows the customer to shop according to their own requirements.

From such an introduction which describes above, researcher is interested in the study of Consumer Buying Behaviors of household Plastic Furniture and bring the results of the study to suggest as a guidelines to entrepreneur in planning to sale household plastic furniture that meet a specific customer need or request.

\section{The Purpose of the Study}

1. To study Consumer Buying Behaviors of Household Plastic Furniture

2. To study the marketing mix factors affecting buying behavior of Household Plastic Furniture

\section{Conceptual Frameworks of the Study}

From the study above, the researcher adapted consumer behavior and marketing mix theory, as summary and a conceptual framework to study Consumer Buying Behaviors of Household Plastic Furniture.

Indeoendent Variables

Dependent Variables

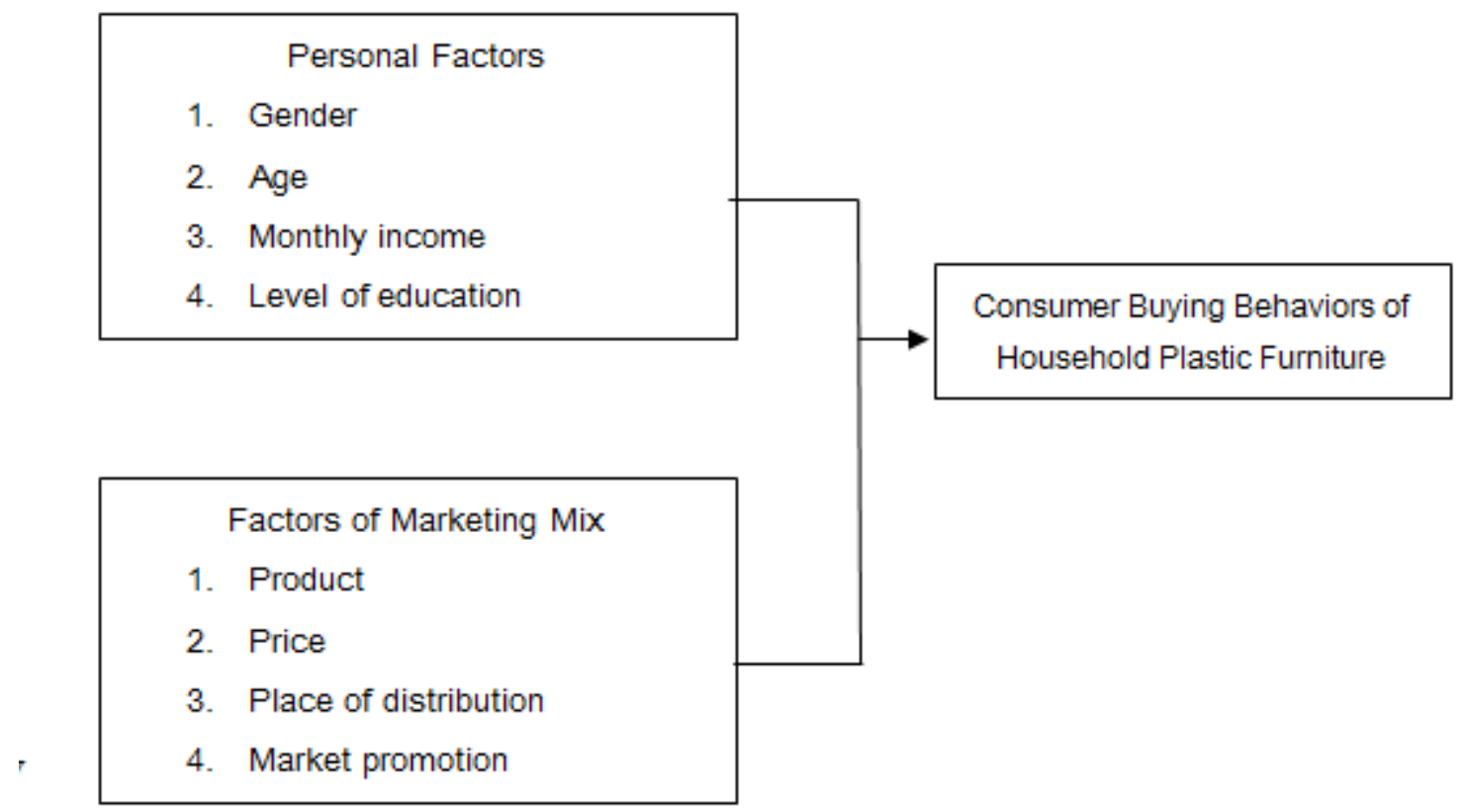

\section{Research Methodology}

\subsection{Sample Selection}

The samples were 400 consumer who purchased household furniture products in Bangkok.

\subsection{Data Collection Procedure}

The questionnaires were distributed to sample of 400 consumer who purchased household furniture products in Bangkok. A total of 400 usable questionnaires were returned back to the researcher, yielding a 100 percent response rate and no missing data. 
Findings indicated that marketing mix factors effecting consumer buying behavior of Household Plastic Furniture

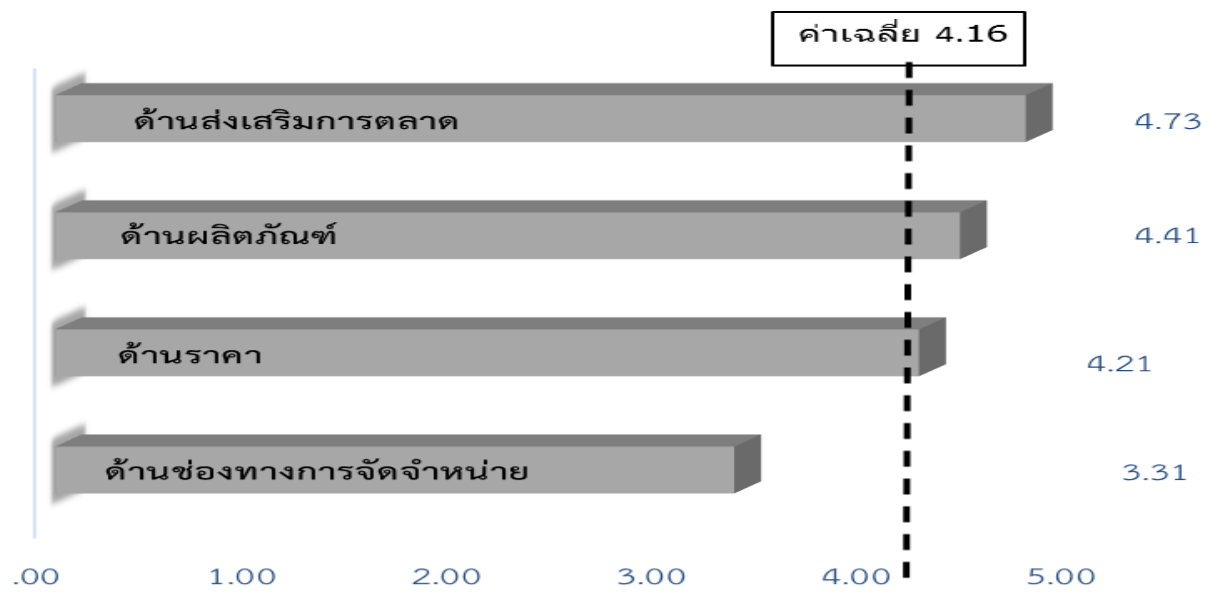

Display the overall picture of marketing mix factors.

It found that the average overall marketing mix factor that affected consumer buying behavior of Household Plastic Furniture was at high level ( average $=4.16$ ) consisted of marketing promotion aspect (average $=4.73$ ), products aspect (average $=4.41$ ), and prices aspect (average $=4.21$ ). As for distribution channel aspect (average $=3.31)$ was in medium level

TABLE I: hypothesis revealed the regression value, the important of marketing mix factors correlated with consumer buying behavior of Household Plastic Furniture

\begin{tabular}{|c|c|c|c|c|c|c|}
\hline \multirow[t]{2}{*}{ Factors of Marketing Mix } & \multicolumn{2}{|c|}{$\begin{array}{l}\text { Unstandardized } \\
\text { Coefficients }\end{array}$} & \multirow{2}{*}{$\begin{array}{c}\begin{array}{c}\text { Standardized } \\
\text { Coefficients }\end{array} \\
\text { Beta }\end{array}$} & \multirow[t]{2}{*}{$\mathrm{t}$} & \multirow[t]{2}{*}{ Sig. } & \multirow[t]{2}{*}{ Test } \\
\hline & $\mathrm{B}$ & Std. Error & & & & \\
\hline $\begin{array}{c}\text { (constant) } \\
\text { Products aspect }\end{array}$ & 0.011 & 0.256 & & 0.43 & 0.966 & \\
\hline Brand name & 0.122 & .0062 & 0.066 & 1.982 & 0.705 & No relationship \\
\hline Modern design & 0.177 & 0.060 & 0.168 & 2.952 & 0.600 & No relationship \\
\hline Guarantee & 0.035 & 0.053 & 0.035 & 0.665 & 0.506 & No relationship \\
\hline According to customer need & 0.041 & 0.053 & 0.041 & 0.775 & 0.439 & No relationship \\
\hline Color appropriate to use & 0.144 & 0.046 & 0.172 & 3.125 & 0.200 & No relationship \\
\hline $\begin{array}{l}\text { Durable to use } \\
\text { Prices aspect }\end{array}$ & 0.228 & 0.049 & 0.244 & 4.654 & 0.602 & No relationship \\
\hline $\begin{array}{l}\text { Appropriate price } \\
\text { Product quality }\end{array}$ & 0.068 & 0.053 & 0.064 & 1.285 & 0.200 & No relationship \\
\hline Wide range of prices & 0.123 & 0.056 & 0.109 & 2.189 & 0.029 & Relationship \\
\hline Price appropriate to product & 0.050 & 0.056 & 0.045 & 0.886 & $*$ & No relationship \\
\hline $\begin{array}{l}\text { Comparable price } \\
\text { Distribution Channel }\end{array}$ & 0.074 & 0.049 & 0.070 & 1.502 & $\begin{array}{l}0.376 \\
0.134\end{array}$ & No relationship \\
\hline Distribution channel nationwide & 0.185 & 0.055 & 0.164 & 3.377 & & Relationship \\
\hline Offered at department store & 0.090 & 0.058 & 0.076 & 1.560 & 0.001 & No relationship \\
\hline $\begin{array}{l}\text { Purchase through internet } \\
\text { Marketing Promotion }\end{array}$ & 0.085 & 0.053 & 0.090 & 1.604 & $\begin{array}{c}* \\
0.120\end{array}$ & No relationship \\
\hline Discount price during promote & 0.058 & 0.055 & 0.062 & 1.049 & 0.109 & No relationship \\
\hline Introduction product rep. & 0.111 & 0.050 & 0.107 & 2.226 & & Relationship \\
\hline $\begin{array}{l}\text { Discount during new products } \\
\text { Discount when buying in large } \\
\text { quantity }\end{array}$ & 0.062 & 0.053 & 0.056 & 1.183 & $\begin{array}{l}0.295 \\
0.027 \\
* \\
0.238\end{array}$ & No relationship \\
\hline
\end{tabular}

*Significant level 0.05

Hypothesis testing revealed that factors of marketing mix, such as wide range of prices $($ Sig. $=0.029$ ), distribution channel, such as stores nationwide (Sig. $=0.001$ ), and marketing promotion, such as a sale representative to introduce new products $(\mathrm{Sig} .=0.027)$ correlated with consumer buying behavior of Household Plastic Furniture at significant level 0.05 . 


\section{Summary of Study Results}

The primary purpose of the study was to determine customer buying behaviors and marketing factors of household plastic furniture. The samples were selected from 400 customers who were consumer lived in Bangkok area by using a check list and rating scale questionnaire as a tool. Statistical application used for data analysis was percentage, mean, standard deviation, Chi-Square, and regression analysis.

\section{Summary of the Study of Consumer Buying Behaviors of Household Plastic Furniture}

Overview of marketing mix factors found that the average overall factors that affects consumer behavior of household plastic furniture were in the high level, such as marketing promotion, products, prices, but distribution channel was in medium level.

Products aspect: study revealed that durable product, product guarantee, color applicable with the products, and famous brand names which average picture of opinions were at high level.

Prices aspect: study revealed that comparable prices to other competitors, appropriate with quality of products which average picture of opinions were at high level, and wide range of prices was at medium level.

Distribution channel aspect: study revealed that there are distribution channel nationwide which was in high level of opinion, and e-commerce channel was in low level of opinion.

Marketing promotion aspect: study revealed that offered discount prices during new products introduction, discount price when buying in large quantity of products which average picture of opinions were at high level.

\section{Recommendations from the Study}

Recommendations from this study were that entrepreneur should prioritize to modern product design with styles, meet the needs of consumer preferred, comparable prices, offer products nationwide, discount prices when offer new products, free gift with purchased, and advertising through all media channels.

\section{Suggestions for Future Study}

From this study researcher chose a specific population group, suggestion for future study should select different demographics area in order to compare the results of the analysis results for the benefit of bringing the result and create a guideline for entrepreneur to follow.

\section{References}

[1] Thongchai Santivong. (2549). Consumer behavior of marketing. (11 ${ }^{\text {st }}$ edition), Prachum chang Publisher, Bangkok.

[2] Siriwan Saerirat, Parinrak Sitanont, Suppakorn Saerirat, and Ongard Patavanich. (2546). New Era of Marketing Management, Thammasarn publisher, Bangkok.

[3] Siriwan Saerirat \& Associate. (2543). Marketing principles. Theerafilm and Chitex Co., Ltd., Publisher, Bangkok.

[4] Siriwan Saerirat, Parinrak Sitanont, Suppakorn Saerirat, and Ongard Patavanich.(2541). Marketing Strategy and marketing management, Theerafilm and Chitex Co., Ltd., $\quad$ Publisher, Bangkok.

[5] Saeri Vongmonta. (2542). Analyze consumer behavior, Theerafilm and Chitex Co., Ltd., Publisher, Bangkok.

[6] Surasith Intae. (2551). Study relationship between marketing communication and traveling Behavior of Umphor Mae Sarieng, Mae Hong Sorn Province, Thesis, Master of Business Administration, Burapha University publisher.

[7] Prathana Suanboon. (2553). Factors affecting consumer behavior on purchasing furniture in Ratchaburi Province, Thesis, Master of Business Administration, Ratchaphat Moo ban Jormbung, publisher.

[8] Chinchai Kajonnatikul. (2553). Factors affecting consumer behavior on purchasing home Decoration furniture in Suphanburi Province, Thesis, Master of Business Administration, Kasetsart University pulisher.

[9] Arunwan Chombut. (2555). Factors affecting consumer behavior on purchasing sofa furniture In Pranakorn Sri Ayuthaya Province, Thesis, Master of Business Administration, Ratchaphat Valailongkorn University, publisher. 